\title{
Analysis of the Upper and Lower Limbs Movement in Elite Fencing Attack Skills
}

\author{
Taewhan $\mathrm{Kim}^{1}$ and Sanghyup Choi ${ }^{2 *}$ \\ ${ }^{1}$ Korea Institute of Sport Science, Seoul, Korea \\ ${ }^{2}$ Center for Sport Science in Jeju, Jeju, Korea
}

\section{Article Info}

Received 2021.07.21.

Revised 2021.09.16.

Accepted 2021.09.29.

Correspondence*

Sanghyup Choi

koreash@icloud.com

\section{Key Words}

Marche,

Fente,

Fencing,

Movement time,

Velocity

이 논문은 김태완(2011)의 연구보고서 중 일부를 발췌하였으며, 국민체육진흥공단 한국스포츠정책과학원사업비에 의하여 연구되었음.
PURPOSE This study aims to help improve performance by comparing and analyzing the kinematic variables for each upper and lower extremities segment when two groups of players attack the national women's fencing players in a match situation. METHODS This study divided the movement time, movement time ratio, Fente step length change, angle factor at each event, and velocity factor of the fencing point of a sword at each event into the Olympic medalists' group (Group A) and the international competition winners group (Group B) during the fencing Marche Fente. An independent t-test was performed for each factor, and the results were compared. RESULTS As a result, the difference between the two groups in movement time was statistically significant in the front of the foot in the velocity factor. However, no statistical significance was found between the two groups in the front angle of the trunk, the elbow angle, and the knee angle. CONCLUSIONS This indicates that group $A$ and group $B$ are both outstanding players with the best performance, so they are similar in the details of the movements except for the very slight difference in time and velocity. Therefore, the average of the result values of the joint angle will be a feedback index for fencing beginners or education subjects who are now starting to fencing.
서론

펜싱경기 종목 중 플뢰레(Fleuret)는 민첩성을 주로 하는 프랑스식에 근 거를 두고 있으며, 에페(Epee)와 사브르(Sabre)는 이탈리아와 헝가리의 검법에 근거를 두고 있다(Castello, 1972). 우리나라 펜싱은 유럽 강국 의 선수들과의 체격과 기술의 차이에도 불구하고 2000 년 시드니올림픽 에서 남자 플뢰레 금메달, 2008년 베이징올림픽에서 여자 플뢰레 은메 달, 2010년 세계선수권대회에서 비유럽권 선수로는 사상 처음으로 남자 사브르 금메달, 여자 플뢰레 동메달을 추가한 것을 비롯해 여자 플뢰레 와 여자 에페 단체전에서도 동메달을 획득하는 등 한국 펜싱 사상 역대 최고 성적인 종합 5위라는 기록 달성하였다(Kim, 2011).

이런 상승세를 그대로 이어 2012 런던올림픽에서 한국 펜싱출범이래 역사상 최고 성적인 금 2 개, 은 1 개, 동 3 개로 출전한 3 종목 모두 남녀에 서 메달을 획득하는 기록을 냈다.

이러한 펜싱 경기는 백색 유니폼을 입고 머리에는 마스크를 쓰며, 무 기를 사용하여 몸을 지키는 본능에서 출발하여 스피드 한 풋워크(footwork)에 따른 정확한 기회 포착 및 기술시도에 의해 $1 / 25$ 초의 터치로써 승패가 결정되어지는 스피드한 경기이다. 그렇기 때문에 빠른 상황판단
능력, 민첩성, 순발력 및 정확성이 요구되는 경기이며, 하루에 수차례씩 경기를 반복 수행해야 하기 때문에 유산소성과 무산소성이 두루 겸비되 어야 하는 스포츠종목이다(Roi \& Bianchedi, 2008). 펜싱 경기에서 가 장 중요한 기술은 찌르기 기술인데, 신체의 전후 이동을 통한 상대방과 탐색전을 통해 상대의 반응과 습관을 빨리 파악하여 최대한 빈틈을 찾아 공격해야 한다. 따라서, 경기 중 정확한 동작수행시간(response time) 과 전신의 협응력(coordination)이 승패에 결정적인 영향을 미칠 수 있 다. 동작수행시간은 반응시간(reaction time)과 동작시간(movement time)의 합이고, 반응시간은 자극으로부터 실제 근수축이 일어나 반응 을 시작하기까지의 시간을 말하며, 동작시간은 동작의 개시로부터 완료 된 시간까지를 말한다. 즉, 펜싱 선수들의 단순반응시간과 기본공격기술 동작시간과는 확실한 상관성이 있고, 펜싱선수들의 기본기술 동작시간 과 복합반응시간과의 상관이 높다고 볼 수 있다(Kang, 1987; Teichor, 1984; Park, 1974).

일반적으로 펜싱경기는 주로 한쪽 방향으로 공격과 방어를 병행하는 동작 형태인데, 신체의 안정 상태가 불균형 상태에서 중심을 한쪽으로 두고 기술을 수행하는 동작이 많은 종목이기 때문에 공격 기술 중 런지 동작(팡트)이 가장 많이 사용되고 있고, 이러한 동작이 공격선수가 상대 
에게 가장 많은 유효성을 주는 동작이라고 하였다(Stewart \& Kopetka, 2005). 특히 팡트(앞다리를 차주면서 뒷다리를 펴주는 공격동작)동작 은 빠르고 폭발적인 풋워크(foot work)의 결단성, 찌르기(런지 Lunge) 의 정확성과 스피드가 중요시되는 동작이며(Ahn, 1984), 아따끄(공격) 와 빠라드(방어) 기술을 수행할 때 몸통의 움직임보다는 상지 분절(위 팔, 아래팔, 손)의 기여가 크므로 분절의 움직임 패턴을 이해하는 것이 중요하다(Lee et al., 2009). 펜싱 동작에 관련된 선행연구들을 살펴보 면 Chung(2019)은 숙련자와 비숙련자간의 운동학적 분석을 통해 경기 력 향상을 위한 정량적 자료를 제공하였고, $\operatorname{Ahn}(2003)$ 은 마르쉬 팡트 동작과 마르쉬 후레쉬 동작에 대한 운동학적 분석을 통해 기술별 특성 을 분석하였다. 국외의 연구로는 Gholipour 등(2008)은 우수선수와 비 우수선수의 펜싱 런지 동작을 분석을 통해 우수한 선수일수록 런지 길 이가 길어진다고 보고하였으며, 런지 길이의 증가는 햄스트링 근육의 강화가 요구된다고 보고하였다. Zhang 등(1999)은 에페 종목의 팡트 동작을 주제로 엘리트선수와 비엘리트 선수들 간의 운동학적 비교를 통 해 엘리트선수들의 경우 런지 길이가 길게 나타나고 엉덩이관절의 이동 속도가 빠르게 나타난다는 결과를 보고하였다. Zappa 등(1999)은 사 브르 종목의 히팅 동작의 운동학적 분석을 통해 동작에 대한 정량적인 자료를 제공하였다. 또한 Sinclair 등(2010)은 총 4가지(일반운동화, 펜 싱화) 운동화를 싣고 펜싱 런지 동작 시 경골에 발생되는 충격량 크기의 차이를 연구하였다.

위와 같이 펜싱과 관련된 대부분의 운동학 및 운동역학적 선행 연구들 을 살펴보면, 대부분의 연구들이 실험실 상황에서 상대 선수 없이 혼자 서 공격하는 동작들을 분석하는데 국한되어 왔다. 또한 앞에서 제시한 엘리트 선수들의 펜싱 기술의 생체역학적 분석에서 같은 수준의 엘리트 선수들끼리도 찌르기의 시간변인이나 움직임의 패턴이 약간씩 다름을 알 수 있었다(Zhang et al., 1999). 따라서 본 연구에서는 실전과 유사한 대련 상황으로 실험 환경을 구축하여 국가대표 여자 플뢰레 선수들이 대 련 시 올림픽 메달리스트 그룹과 국제대회 입상자 그룹 간 공격 시 상지 와 하지의 분절(segment)별 메커니즘에 대해 운동학적 변인을 비교 분 석하여 경기력 향상에 도움을 주고자 한다. 두 그룹이 매우 유사한 실력 에도 불구하고 세계대회의 수준에서 결과의 차이를 보이는 바, 두 그룹 간의 비교를 통한 차이점과 유사점에 대해 분석한 결과를 밝혀내, 더 정 확한 펜싱 교육 피드백 자료를 구성하는데 본 연구의 목적이 있다.

\section{연구방법}

\section{연구 대상자}

본 연구의 연구대상자는 자발적으로 연구에 참여할 수 있도록 연구 참 여 동의서에 서명한 국가대표 중에서 여자 플뢰레 6명(신장 평균 164.0 $\pm 8.4 \mathrm{~m}$, 체중 평균 $56.4 \pm 10.4 \mathrm{~kg}$, 연령 평균 $28.6 \pm 2.1 \mathrm{yrs})$ 을 대상으로 선정하였다. 먼저 여자 선수 중 3명의 최우수 선수(올림픽 메달리스트) 를 $\mathrm{A}$ 그룹으로 설정하였고, 나머지 3명의 선수(국제대회 입상자)를 우수 그룹(B그룹)으로 설정하여 분석하였다.

\section{실험 절차}

펜싱 공격기술 시 상지와 하지의 움직임 분석을 위해 동작분석시스템을
활용하였다. 펜싱의 공격기술동작 파악을 위해 먼저 영상분석에 필요한 공간 좌표 설정을 None Linear Transformation(NLT) 기법을 사용하 여 연구 대상자의 실험동작을 완전히 포함할 수 있을 정도의 범위까지 Calibration을 하였다. 운동학적 및 운동역학적 변인을 분석을 위하여 전, 후, 좌, 우, 대각선 방향으로 리얼타임 적외선 카메라(Motion I.R., Eagle4) 12대를 설치하였으며, 부가적으로 실험전체 장면의 녹화를 위 해 실험 측면에 디지털캠코더(PD-170, Panasonic)를 설치하였다. 이 때 적외선 카메라의 샘플링비율은 초당 $120 \mathrm{~Hz}$ 로 설정하였고, 영상자료 는 Cortex 1.3 프로그램(Motion Analysis, USA)을 사용하여 동조하였 다(Fig. 1). 인체를 16 개의 분절로 이루어진 강체로 규정하였으며 Helen Hayes Marker Set 방식을 사용하여 인체에 직경 $2 \mathrm{~cm}$ 의 31 개의 반사 마커와 칼에 2 개의 반사마커를 부착하여 관절중심 계산을 위한 해부학 적 자세(anatomical position)에서 캘리브레이션(calibration)을 실시 하였다. 이후 실험에서는 하지의 내측 마커 4 개를 제외한 29 개를 이용 하여 위치좌표를 획득하였으며, 본 연구에서 연구결과의 신뢰도를 위해 실제 경기처럼 펜싱 대련 상황과 유사하게 환경을 조성하고 공격 기술 중 가장 많이 사용되는 마르쉬 팡트 동작만을 선별하여 대련 중 득점을 성공시킨 3회 동작을 평균(칼끝이 몸통의 유효면에 닿아서 득점이 된 순 간)으로 계산하여 분석하였다. 또한 3차원 분석의 정확성을 위해 실험실 내에서의 측정으로 국한하였다.

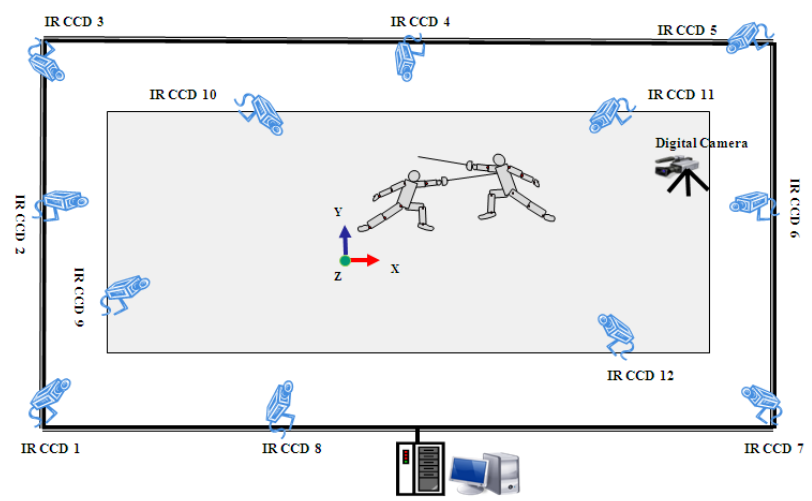

Fig. 1. Motion analysis set up position

Table 1. Subjects information

\begin{tabular}{|c|c|c|c|}
\hline Group & $\mathrm{N}$ & Weight $(\mathrm{kg})$ & $\operatorname{Height}(\mathrm{cm})$ \\
\hline \multirow{4}{*}{ A } & NOO & 45 & 155 \\
\hline & JOO & 58 & 169 \\
\hline & $\mathrm{OOO}$ & 67 & 175 \\
\hline & Mean \pm SD & $56.7 \pm 11.1$ & $166.3 \pm 10.3$ \\
\hline \multirow{4}{*}{ B } & $\mathrm{SOO}$ & 59 & 170 \\
\hline & LOO & 54 & 165 \\
\hline & LOO & 50 & 163 \\
\hline & Mean \pm SD & $54.3 \pm 4.5$ & $166.0 \pm 3.6$ \\
\hline
\end{tabular}




\section{자료 분석}

자료 분석을 위한 영상분석은 None Linear Transformation(NLT) 기 법을 사용하였으며, 측정된 자료는 실제 동작을 시작 시 영상분석 신호 의 동조를 위해 동조시스템박스(NI USB-6218 M Series Multifunction DAQ National Instruments)를 사용하였다. 또한 영상자료는 Cortex 1.3 프로그램(Motion Analysis, USA)을 사용하여 동조하였으며, 원자 료(raw data, C3D file)는 Visual 3D 프로그램을 사용하여 분석변인들 을 계산하였다. 이때 차단주파수는 Butterworth 4th low-pass $10 \mathrm{~Hz}$ 로 스무딩하였다.

\section{분석구간, 각도정의, 변인}

본 연구에서 대상자들의 공격기술 분석을 위하여 〈Fig. 2 〉와 같이 동작 의 시작 직전 시점(e1), 오른발 뒤꿈치가 지면에 닿는 시점(e2), 왼발 앞 꿈치가 지면에서 떨어지는 시점(e3), 왼발 앞꿈치가 지면에 닿는 시점 (e4), 오른발 뒤꿈치가 지면에 닿는 시점(e5) 그리고 칼이 유효면에 닿는 시점(e6) 총 6개의 Event와 각 시점 간의 구간인 5개 Phase로 구분하여
분석하였다. 또한 본 연구에서 분석된 각도변인은 몸통 전경각, 팔꿈치 각, 무릎각으로 설정하였다(〈Fig. 3〉). 변인은 동작수행 시간과 비율, 보 폭의 변화(〈Fig. 4〉), 신체 각도 요인, 속도 요인이다. 속도 요인에서 칼 끝 속도와 발의 속도는 각 이벤트별 측정을 하였으며, 아래의 식을 이용 하여 X, Y, Z 성분별 속도를 구한 후 이를 합성하여 속도를 계산하였다.

\section{자료 처리}

본 연구에서 데이터 분석의 주요한 목적은 각 이벤트와 국면별 공격 기술에 대한 시간변인과 움직임변인을 최우수그룹과 우수그룹 간 비 교하여 검증하는 것이다. 분석 결과 값은 먼저 모수 검증을 하기 위해 Kolmogorov-Smirnov와 Shapiro-Wilk 검증을 실시하였고, 유의확률 이 모든 변인에서 .05보다 크게 도출되어 본 연구의 표본은 정규분포를 이루었기에 독립 t-검정을 실시하여 결과 값을 제시하였다. 모든 유의확 률은 .05 미만으로 설정하였다.

$$
V=\sqrt{\left(V_{x}^{2}+V_{r}^{2}+V_{z}^{2}\right)}
$$

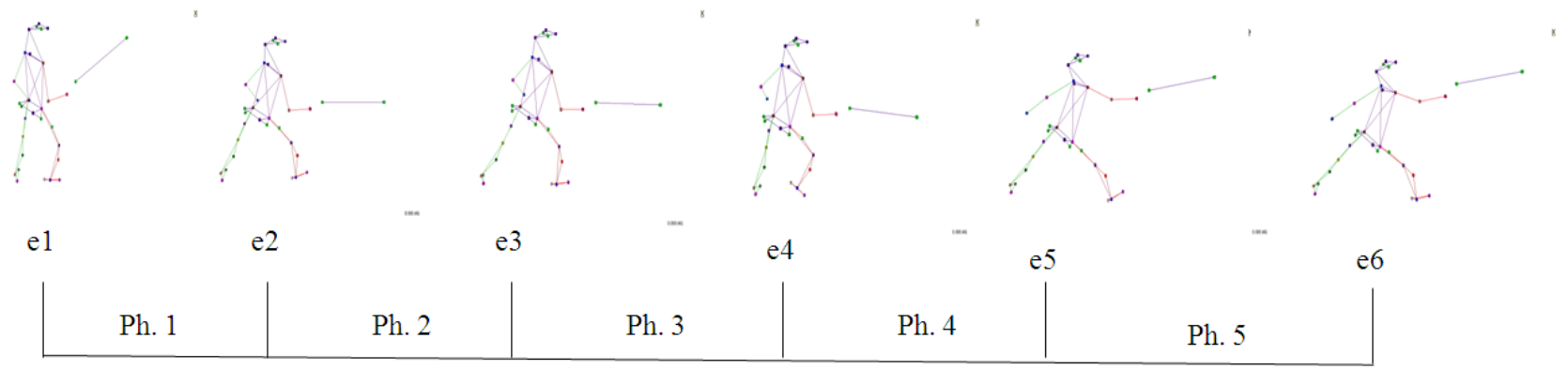

Fig. 2. Event and Phase

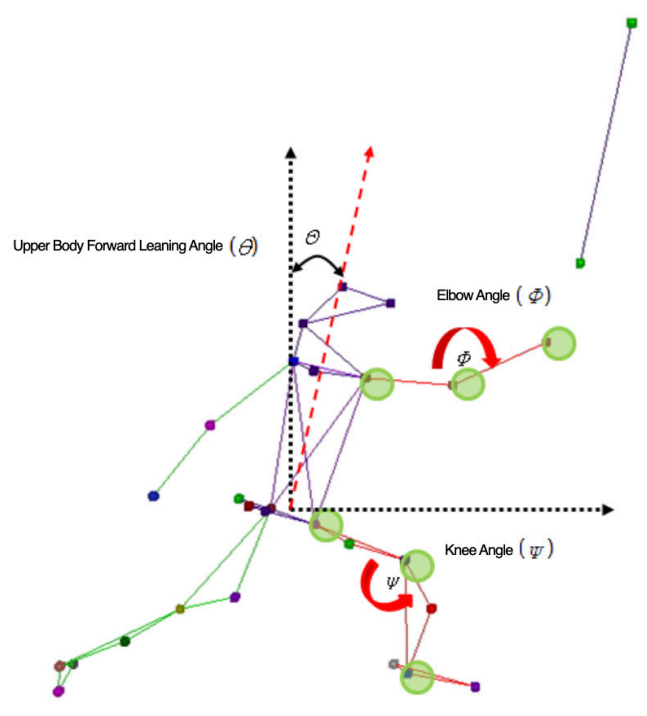

Fig. 3. Definition of Joint Angles

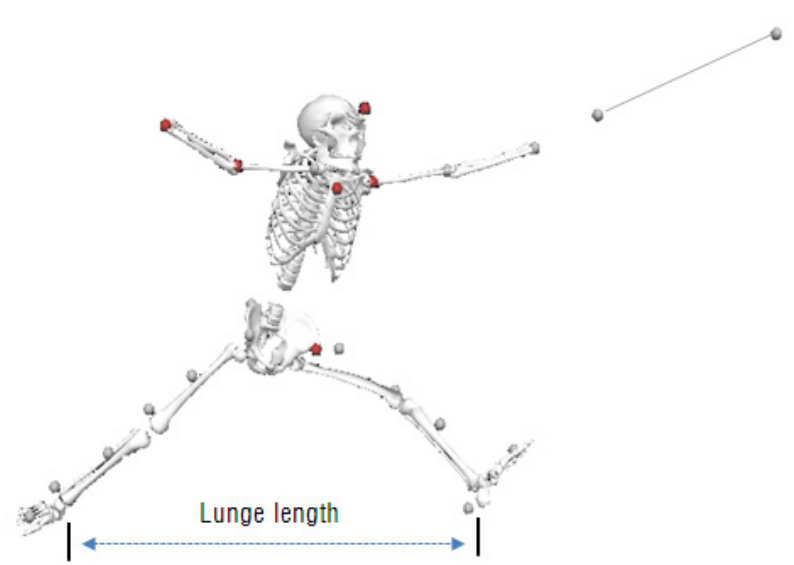

Fig. 4. Definition of lunge length 


\section{연구결과}

\section{동작수행 시간}

마르쉬 팡트 동작 시 구간별 소요시간과 비율은 〈Table 2, 3〉과 같다.

그룹에 따른 주요 변수에 유의한 차이를 보이는지 검증하고자 독립표 본 t-검정을 실시하였다. 그 결과 Phase 4(왼발 앞꿈치가 지면에 닿는 시점 오른발 뒤꿈치가 지면에 닿는 시점)에서 동작수행 소요시간이 유 의한 차이를 보였고, $(\mathrm{t}=-2.910, \mathrm{p}<.05), \mathrm{A}$ 그룹( $\mathrm{M}=0.19 \mathrm{sec}), \mathrm{B}$ 그룹( $\mathrm{M}$ $=0.23 \mathrm{sec}$ 로 $\mathrm{A}$ 그룹이 더 빠른 동작 수행 시간을 보였다. Phase 4 를 제 외한 나머지 Phase에서는 통계적으로 유의한 차이를 보이지 않았다. 총 소요 시간은 $\mathrm{A}$ 그룹 $(\mathrm{M}=0.82 \mathrm{sec})$ 이 $\mathrm{B}$ 그룹 $(\mathrm{M}=0.89 \mathrm{sec})$ 에 비해 더 짧은 시간을 나타냈다.

동작 수행 시간 비율에서도 Phase 4(t=-3.191, p<.05)에서 통계적으 로 유의한 차이가 나타나, $\mathrm{A}$ 그룹( $\mathrm{M}=22.81 \%)$ 이 B그룹(M=25.29\%) 보 다 더 짧은 시간 비율을 보였다.

Table 2. Movement time (sec)

\begin{tabular}{|c|c|c|c|c|c|c|}
\hline Subjects & Group & $\begin{array}{c}\text { Number of } \\
\text { Samples }\end{array}$ & Mean & $\begin{array}{l}\text { Standard } \\
\text { Deviation }\end{array}$ & $\mathrm{t}$ & $\mathrm{p}$ \\
\hline \multirow{2}{*}{ Phase 1} & A & 3 & 0.42 & 0.08 & \multirow{2}{*}{0.368} & \multirow{2}{*}{0.732} \\
\hline & B & 3 & 0.40 & 0.05 & & \\
\hline \multirow{2}{*}{ Phase 2} & A & 3 & 0.06 & 0.04 & \multirow{2}{*}{-0.254} & \multirow{2}{*}{0.812} \\
\hline & B & 3 & 0.06 & 0.02 & & \\
\hline \multirow{2}{*}{ Phase 3} & $\mathrm{~A}$ & 3 & 0.14 & 0.04 & \multirow{2}{*}{-1.455} & \multirow{2}{*}{0.219} \\
\hline & B & 3 & 0.19 & 0.05 & & \\
\hline \multirow{2}{*}{ Phase 4} & A & 3 & 0.19 & 0.01 & \multirow{2}{*}{$-2.910 *$} & \multirow{2}{*}{0.044} \\
\hline & B & 3 & 0.23 & 0.02 & & \\
\hline \multirow{2}{*}{ Phase 5} & A & 3 & 0.02 & 0.01 & \multirow{2}{*}{1.342} & \multirow{2}{*}{0.251} \\
\hline & B & 3 & 0.01 & 0.01 & & \\
\hline \multirow{2}{*}{ Total } & A & 3 & 0.82 & 0.02 & \multirow{2}{*}{-1.006} & \multirow{2}{*}{0.371} \\
\hline & B & 3 & 0.89 & 0.11 & & \\
\hline
\end{tabular}

Table 3. Movement time ratio (\%)

\begin{tabular}{|c|c|c|c|c|c|c|}
\hline Subjects & Group & $\begin{array}{c}\text { Number of } \\
\text { Samples }\end{array}$ & Mean & $\begin{array}{l}\text { Standard } \\
\text { Deviation }\end{array}$ & $\mathrm{t}$ & $\mathrm{p}$ \\
\hline \multirow{2}{*}{ Phase 1} & A & 3 & 51.38 & 10.22 & \multirow{2}{*}{0.895} & \multirow{2}{*}{0.421} \\
\hline & B & 3 & 45.40 & 5.43 & & \\
\hline \multirow{2}{*}{ Phase 2} & A & 3 & 6.66 & 5.01 & \multirow{2}{*}{-0.149} & \multirow{2}{*}{0.889} \\
\hline & B & 3 & 7.13 & 1.97 & & \\
\hline \multirow{2}{*}{ Phase 3} & A & 3 & 16.39 & 3.83 & \multirow{2}{*}{-1.516} & \multirow{2}{*}{0.204} \\
\hline & B & 3 & 20.97 & 3.56 & & \\
\hline \multirow{2}{*}{ Phase 4} & A & 3 & 22.81 & 1.14 & \multirow{2}{*}{$-3.191^{*}$} & \multirow{2}{*}{0.033} \\
\hline & B & 3 & 25.29 & 0.73 & & \\
\hline \multirow{2}{*}{ Phase 5} & A & 3 & 2.76 & 1.43 & \multirow{2}{*}{1.806} & \multirow{2}{*}{0.145} \\
\hline & B & 3 & 1.22 & 0.37 & & \\
\hline
\end{tabular}

\section{보폭 변화}

마르쉬 팡트 동작 시 각 국면별에 따른 보폭의 변화는 〈Table 4〉와 같 다. 그룹에 따른 보폭 변화 변인에서 유의한 차이를 보이는지 검증하고 자 독립표본 t-검정을 실시한 결과 모든 Phase에서 유의한 차이가 나타 나지 않았다.

Table 4. Fente Step Length (cm)

\begin{tabular}{|c|c|c|c|c|c|c|}
\hline Subjects & Group & $\begin{array}{l}\text { Number of } \\
\text { Samples }\end{array}$ & Mean & $\begin{array}{l}\text { Standard } \\
\text { Deviation }\end{array}$ & $\mathrm{t}$ & $\mathrm{p}$ \\
\hline \multirow{2}{*}{ Event 1} & A & 3 & 41.61 & 2.81 & \multirow{2}{*}{1.638} & \multirow{2}{*}{0.177} \\
\hline & B & 3 & 38.35 & 2.00 & & \\
\hline \multirow{2}{*}{ Event 2} & A & 3 & 88.70 & 13.99 & \multirow{2}{*}{-0.796} & \multirow{2}{*}{0.471} \\
\hline & B & 3 & 95.28 & 3.09 & & \\
\hline \multirow{2}{*}{ Event 3} & A & 3 & 83.95 & 12.24 & \multirow{2}{*}{-0.871} & \multirow{2}{*}{0.433} \\
\hline & $\mathrm{B}$ & 3 & 90.26 & 2.80 & & \\
\hline \multirow{2}{*}{ Event 4} & $\mathrm{~A}$ & 3 & 43.43 & 6.98 & \multirow{2}{*}{1.221} & \multirow{2}{*}{0.289} \\
\hline & B & 3 & 33.43 & 12.36 & & \\
\hline \multirow{2}{*}{ Event 5} & A & 3 & 129.40 & 9.10 & \multirow{2}{*}{-0.183} & \multirow{2}{*}{0.864} \\
\hline & B & 3 & 130.40 & 2.47 & & \\
\hline \multirow{2}{*}{ Event 6} & A & 3 & 129.90 & 10.08 & \multirow{2}{*}{0.060} & \multirow{2}{*}{0.955} \\
\hline & B & 3 & 129.55 & 2.31 & & \\
\hline
\end{tabular}

각도 요인

마르쉬 팡트 동작 시 각 시점별 몸통전경각, 팔꿈치각, 무릎각은 〈Table $5,6,7>$ 과 같다. 통계분석 결과 두 그룹 간 모든 각도 요인과 모든 Event 구간에서 유의한 결과를 나타내지 못하였다.

Table 5. Upper Body Forward Leaning Angle (degree)

\begin{tabular}{|c|c|c|c|c|c|c|}
\hline Subjects & Group & $\begin{array}{c}\text { Number of } \\
\text { Samples }\end{array}$ & Mean & $\begin{array}{l}\text { Standard } \\
\text { Deviation }\end{array}$ & $\mathrm{t}$ & $\mathrm{p}$ \\
\hline \multirow{2}{*}{ Event 1} & A & 3 & 87.87 & 2.21 & \multirow{2}{*}{-1.376} & \multirow{2}{*}{0.241} \\
\hline & B & 3 & 90.73 & 2.84 & & \\
\hline \multirow{2}{*}{ Event 2} & A & 3 & 77.82 & 5.04 & \multirow{2}{*}{0.463} & \multirow{2}{*}{0.667} \\
\hline & B & 3 & 75.66 & 6.32 & & \\
\hline \multirow{2}{*}{ Event 3} & A & 3 & 77.40 & 4.36 & \multirow{2}{*}{0.550} & \multirow{2}{*}{0.612} \\
\hline & B & 3 & 74.86 & 6.69 & & \\
\hline \multirow{2}{*}{ Event 4} & A & 3 & 78.69 & 4.07 & \multirow{2}{*}{0.195} & \multirow{2}{*}{0.855} \\
\hline & B & 3 & 77.73 & 7.48 & & \\
\hline \multirow{2}{*}{ Event 5} & A & 3 & 74.68 & 6.28 & \multirow{2}{*}{0.136} & \multirow{2}{*}{0.898} \\
\hline & B & 3 & 73.69 & 10.99 & & \\
\hline \multirow{2}{*}{ Event 6} & A & 3 & 74.41 & 4.94 & \multirow{2}{*}{0.131} & \multirow{2}{*}{0.902} \\
\hline & $\mathrm{B}$ & 3 & 73.52 & 10.73 & & \\
\hline
\end{tabular}


Table 6. Elbow Angle (degree)

\begin{tabular}{|c|c|c|c|c|c|c|}
\hline Subjects & Group & $\begin{array}{c}\text { Number of } \\
\text { Samples }\end{array}$ & Mean & $\begin{array}{l}\text { Standard } \\
\text { Deviation }\end{array}$ & $\mathrm{t}$ & $\mathrm{p}$ \\
\hline \multirow{2}{*}{ Event 1} & A & 3 & 90.71 & 6.36 & \multirow{2}{*}{0.862} & \multirow{2}{*}{0.437} \\
\hline & B & 3 & 86.47 & 5.67 & & \\
\hline \multirow{2}{*}{ Event 2} & A & 3 & 94.72 & 4.73 & \multirow{2}{*}{-0.350} & \multirow{2}{*}{0.744} \\
\hline & B & 3 & 99.14 & 21.33 & & \\
\hline \multirow{2}{*}{ Event 3} & A & 3 & 96.31 & 5.59 & \multirow{2}{*}{-0.442} & \multirow{2}{*}{0.681} \\
\hline & B & 3 & 101.79 & 20.70 & & \\
\hline \multirow{2}{*}{ Event 4} & A & 3 & 106.37 & 7.50 & \multirow{2}{*}{-0.922} & \multirow{2}{*}{0.409} \\
\hline & B & 3 & 117.53 & 19.58 & & \\
\hline \multirow{2}{*}{ Event 5} & A & 3 & 156.68 & 9.04 & \multirow{2}{*}{0.394} & \multirow{2}{*}{0.714} \\
\hline & B & 3 & 154.14 & 6.59 & & \\
\hline \multirow{2}{*}{ Event 6} & A & 3 & 156.65 & 7.47 & \multirow{2}{*}{0.457} & \multirow{2}{*}{0.671} \\
\hline & B & 3 & 154.12 & 6.04 & & \\
\hline
\end{tabular}

Table 7. Knee Angle (degree)

\begin{tabular}{|c|c|c|c|c|c|c|}
\hline Subjects & Group & $\begin{array}{c}\text { Number of } \\
\text { Samples }\end{array}$ & Mean & $\begin{array}{c}\text { Standard } \\
\text { Deviation }\end{array}$ & $\mathrm{t}$ & $\mathrm{p}$ \\
\hline \multirow{2}{*}{ Event 1} & A & 3 & 137.63 & 7.31 & \multirow{2}{*}{0.818} & \multirow{2}{*}{0.459} \\
\hline & B & 3 & 133.42 & 5.11 & & \\
\hline \multirow{2}{*}{ Event 2} & A & 3 & 144.64 & 9.42 & \multirow{2}{*}{-0.018} & \multirow{2}{*}{0.987} \\
\hline & B & 3 & 144.77 & 9.13 & & \\
\hline \multirow{2}{*}{ Event 3} & A & 3 & 136.64 & 4.49 & \multirow{2}{*}{1.060} & \multirow{2}{*}{0.349} \\
\hline & B & 3 & 132.88 & 4.19 & & \\
\hline \multirow{2}{*}{ Event 4} & A & 3 & 105.78 & 5.85 & \multirow{2}{*}{0.073} & \multirow{2}{*}{0.946} \\
\hline & B & 3 & 105.51 & 2.25 & & \\
\hline \multirow{2}{*}{ Event 5} & A & 3 & 164.69 & 4.94 & \multirow{2}{*}{0.427} & \multirow{2}{*}{0.691} \\
\hline & B & 3 & 162.46 & 7.56 & & \\
\hline \multirow{2}{*}{ Event 6} & A & 3 & 165.41 & 3.50 & \multirow{2}{*}{0.599} & \multirow{2}{*}{0.582} \\
\hline & B & 3 & 163.69 & 3.55 & & \\
\hline
\end{tabular}

속도 요인

마르쉬 팡트 동작 시 각 시점별 칼끝의 속도와 양발(앞, 뒤)의 속도는 〈Table 8, 9, 10〉과 같다. 먼저, 그룹에 따른 속도 요인 중 칼끝 속도에 유의한 차이를 보이는지 검증하고자 독립표본 $\mathrm{t}$-검정을 실시한 결과, 모 든 Event에서 통계적으로 유의한 차이를 보이지 않았다.

다음으로, 그룹에 따른 속도 요인 중 앞발 속도에 유의한 차이를 보이 는지 검증하고자 독립표본 t-검정을 실시한 결과 또한, 모든 Event에서 통계적으로 유의한 차이를 보이지 않았다. 마지막으로 속도 요인 중, 뒷 발의 속도를 $\mathrm{t}$-검정한 결과에서는 유의한 차이가 나타나지 않았다
Table 8. Point of a Sword $(\mathrm{m} / \mathrm{s})$

\begin{tabular}{|c|c|c|c|c|c|c|}
\hline Subjects & Group & $\begin{array}{c}\text { Number of } \\
\text { Samples }\end{array}$ & Mean & $\begin{array}{c}\text { Standard } \\
\text { Deviation }\end{array}$ & $\mathrm{t}$ & $\mathrm{p}$ \\
\hline \multirow{2}{*}{ Event 1} & A & 3 & 0.27 & 0.23 & \multirow{2}{*}{-0.598} & \multirow{2}{*}{0.582} \\
\hline & B & 3 & 0.38 & 0.24 & & \\
\hline \multirow{2}{*}{ Event 2} & A & 3 & 2.19 & 0.55 & \multirow{2}{*}{-0.656} & \multirow{2}{*}{0.547} \\
\hline & B & 3 & 2.45 & 0.39 & & \\
\hline \multirow{2}{*}{ Event 3} & A & 3 & 2.45 & 0.28 & \multirow{2}{*}{0.642} & \multirow{2}{*}{$\begin{array}{l}0.556 \\
0.556\end{array}$} \\
\hline & B & 3 & 2.32 & 0.19 & & \\
\hline \multirow{2}{*}{ Event 4} & A & 3 & 4.91 & 3.77 & \multirow{2}{*}{0.407} & \multirow{2}{*}{0.705} \\
\hline & B & 3 & 3.94 & 1.71 & & \\
\hline \multirow{2}{*}{ Event 5} & A & 3 & 3.20 & 0.58 & \multirow{2}{*}{1.223} & \multirow{2}{*}{0.288} \\
\hline & B & 3 & 2.63 & 0.57 & & \\
\hline \multirow{2}{*}{ Event 6} & A & 3 & 2.69 & 1.36 & \multirow{2}{*}{0.221} & \multirow{2}{*}{0.836} \\
\hline & B & 3 & 2.48 & 0.83 & & \\
\hline
\end{tabular}

Table 9. Front of the Foot $(\mathrm{m} / \mathrm{s})$

\begin{tabular}{|c|c|c|c|c|c|c|}
\hline Subjects & Group & $\begin{array}{c}\text { Number of } \\
\text { Samples }\end{array}$ & Mean & $\begin{array}{c}\text { Standard } \\
\text { Deviation }\end{array}$ & $\mathrm{t}$ & $\mathrm{p}$ \\
\hline \multirow{2}{*}{ Event 1} & A & 3 & 0.09 & 0.12 & \multirow{2}{*}{1.029} & \multirow{2}{*}{0.409} \\
\hline & B & 3 & 0.02 & 0.01 & & \\
\hline \multirow{2}{*}{ Event 2} & A & 3 & 1.04 & 0.19 & \multirow{2}{*}{0.139} & \multirow{2}{*}{0.896} \\
\hline & B & 3 & 1.02 & 0.21 & & \\
\hline \multirow{2}{*}{ Event 3} & A & 3 & 0.77 & 0.14 & \multirow{2}{*}{0.475} & \multirow[t]{2}{*}{0.659} \\
\hline & B & 3 & 0.71 & 0.14 & & \\
\hline \multirow{2}{*}{ Event 4} & A & 3 & 1.86 & 0.25 & \multirow{2}{*}{-1.053} & \multirow[t]{2}{*}{0.352} \\
\hline & B & 3 & 2.32 & 0.72 & & \\
\hline \multirow{2}{*}{ Event 5} & A & 3 & 2.94 & 0.75 & \multirow{2}{*}{0.944} & \multirow{2}{*}{0.399} \\
\hline & B & 3 & 2.45 & 0.50 & & \\
\hline \multirow{2}{*}{ Event 6} & A & 3 & 2.53 & 0.77 & \multirow{2}{*}{0.303} & \multirow{2}{*}{0.777} \\
\hline & B & 3 & 2.38 & 0.34 & & \\
\hline
\end{tabular}

Table 10. Rear of the Foot $(\mathrm{m} / \mathrm{s})$

\begin{tabular}{|c|c|c|c|c|c|c|}
\hline Subjects & Group & $\begin{array}{c}\text { Number of } \\
\text { Samples }\end{array}$ & Mean & $\begin{array}{l}\text { Standard } \\
\text { Deviation }\end{array}$ & $\mathrm{t}$ & $\mathrm{p}$ \\
\hline \multirow{2}{*}{ Event 1} & A & 3 & 0.03 & 0.04 & \multirow{2}{*}{0.601} & \multirow{2}{*}{0.607} \\
\hline & B & 3 & 0.02 & 0.01 & & \\
\hline \multirow{2}{*}{ Event 2} & A & 3 & 0.78 & 0.97 & \multirow{2}{*}{0.869} & \multirow{2}{*}{0.434} \\
\hline & B & 3 & 0.26 & 0.35 & & \\
\hline \multirow{2}{*}{ Event 3} & A & 3 & 2.12 & 0.65 & \multirow{2}{*}{1.033} & \multirow{2}{*}{0.360} \\
\hline & $\mathrm{B}$ & 3 & 1.60 & 0.57 & & \\
\hline \multirow{2}{*}{ Event 4} & A & 3 & 2.36 & 0.87 & \multirow{2}{*}{0.324} & \multirow{2}{*}{0.762} \\
\hline & $\mathrm{B}$ & 3 & 2.12 & 0.91 & & \\
\hline \multirow{2}{*}{ Event 5} & A & 3 & 1.73 & 0.07 & \multirow{2}{*}{0.627} & \multirow{2}{*}{0.565} \\
\hline & B & 3 & 1.55 & 0.49 & & \\
\hline \multirow{2}{*}{ Event 6} & A & 3 & 1.70 & 0.30 & \multirow{2}{*}{0.246} & \multirow{2}{*}{0.818} \\
\hline & B & 3 & 1.61 & 0.56 & & \\
\hline
\end{tabular}




\section{논의}

본 연구는 펜싱 마르쉬 팡트 동작 시 동작수행 시간(구간별 소요시간, 구 간별 소요시간 비율), 국면별 보폭 변화, 각 시점별 각도 요인(상지의 몸 통전경각, 팔꿈치각, 무릎각), 각 시점별 펜싱 칼끝의 속도 요인(앞발과 뒷발)을 올림픽 메달리스트 그룹(A그룹)과 국제대회 입상자 그륩(B그룹) 으로 나누어 각 요인별로 독립 t-검정을 실시하여 결과를 비교하였다.

먼저, 동작수행 시간 중 구간별 소요시간에서는 Phase 4 에서 통계적 으로 유의한 차이를 보였다. 또한 구간별 소요시간 비율에서도 Phase 4 에서 통계적으로 유의한 차이를 보였다. Phase 4 는 왼발 앞꿈치가 지 면에 닿는 시점에서 오른발 뒤꿈치가 지면에 닿는 시점까지인데 $\mathrm{A}$ 그룹 이 B그룹에 비해 더 약 0.04 초 더 짧은 소요시간을 보였고, 전체 비율로 도 A그룹은 $22.81 \%, \mathrm{~B}$ 그룹은 $25.29 \%$ 를 나타냈다. 전체 수행 시간을 보 면, $\mathrm{A}$ 그룹은 0.82 초, $\mathrm{B}$ 그룹은 0.89 초를 나타냈는데 런지 동작의 거의 마지막 동작에서 A그룹이 더 빠른 수행 동작을 보여준 것이다. 또한, 통 계적으로 유의한 차이를 보이진 않았지만 동작수행 시간은 Phase 1 과 5 는 A그룹이 B그룹에 비해 더 긴 소요시간과 비율을 나타냈다. 이는 시작 과 마지막 공격의 정확성을 위해 더 우수한 그룹이 더 긴 시간 비율을 사 용했을 것으로 판단되며, 이를 예측정확성과 관련하여 설명할 수 있는 데 펜싱 초보자는 충분한 사전시각 단서를 활용해야 하는지 파악하지 못 해 단순하게 반응하여 수행시간이 짧게 되고 숙련자는 예측정확성의 확 신도가 높기 때문에 더 많은 정보를 처리한다고 하였는데 목표를 공격 하는 예측정확성을 위해 더 우수한 그룹이 더 많은 시간을 소요했을 것 으로 판단된다(Lee et al., 2018). 또한 관련 연구를 살펴보면, 경력 5년 의 남자 고등부 펜싱선수 3 명과 경력 2년의 고등부 선수 3 명을 대상으로 $16 \mathrm{~mm}$ 무비 카메라를 사용하여 동작분석을 실시한 연구에서 앞 팔을 펴는데 걸리는 시간은 숙련자 0.364 초, 미숙련자 0.221 초로 미숙련자가 떠 빠르게 나타난 것으로 보아 더 정확한 동작을 위해 숙련자에게서 더 많은 시간이 소요됨을 알 수 있었다(Ahn, 1984). 이 결과에서는 대련 중 상대의 움직임을 예상하면서 시작 동작이 수행되어야만 더 정확한 공격 을 수행할 수 있고 이것이 뒤에 이어지는 속도 증가 결과로 나타날 것이 고, 선행 연구에서 팡트 공격 시에는 빠른 동작으로 상대방의 가슴을 찔 러야 하는 특성 때문에 최대한 팡르 신점시킴과 동시에 상체의 기울기를 크게 해야 한다고 했는데 이러한 큰 동작을 실행시키기 위해 동작시간은 두 그룹이 같은 시간을 보였지만 비율적으로는 $\mathrm{A}$ 그룹이 더 긴 시간 비 율을 사용했을 것으로 판단된다. 따라서 공격 상황 시, 더 정확하고 빠른 동작을 위해 수행 준비 시간과 칼이 유효면에 닿는 동작 시간에서 더 많 은 소요시간 비율이 나타난 것으로 사료된다.

다음으로는, 마르쉬 팡트 동작 시 각 국면별에 따른 보폭 변화 결과이 다. 전에 국면에서 통계적으로 유의한 차이를 보이지 않았다. 또한, 각 도 요인에서 몸통의 전경각, 팔꿈치각, 무릎각에서도 통계적으로 유의 한 차이는 나타나지 않았다. 관련된 선행연구에서는 엘리트 펜싱 선수 와 펜싱 초보자 간 팡트 동작 시 운동학적 변인을 비교한 결과 엘리트 선수들에게서 무릎각도의 변화 과정이 초보자와 다르게 변위의 크기 가 크기 나타났고, 런지 동작의 길이가 더 길게 나타난 것을 알 수 있었 다(Harmenberg et al., 1991). 또한, Gholipour 등(2008)의 연구에서 는 펜싱 숙련자와 초보자 간 보폭의 차이가 약 $0.15 \mathrm{~m}$ 차이가 나 숙련자 가 첫 발의 보폭이 더 크다는 것을 볼 수 있었다. 이 밖에도 다수의 연구 에서도 펜싱 숙련자와 초보자 간에서 보폭 및 관절각의 차이를 보였다 (Geil, 2002; Gutierrez-Davila et al., 2013; Morris et al., 2011). 그 러나 본 연구에서 보폭 및 각 관절의 각도 분석 결과와 같이 운동학적 변
인들에서 두 그룹 간 차이가 나타나지 않은 점은 두 그룹 모두 매우 우수 한 기술을 발휘하는 선수들이기 때문이라고 사료된다.

마지막으로 속도 요인(칼끝의 속도, 앞발의 속도, 뒷발의 속도) 전체에 서 통계적으로 유의한 차이가 나타나지 않았다. 통계적 차이는 없었지만 Event 1 에서 A그룹은 $0.27 \mathrm{~m} / \mathrm{s}, \mathrm{B}$ 그룹은 $0.38 \mathrm{~m} / \mathrm{s}$ 를 나타내 B그룹이 더 빠른 칼끝의 속도를 보였다. 이는 동작의 시작 시점인 Event 1 에서 A 그룹의 선수들이 칼의 조작보다는 마르쉬 동작에 더 치중하는 것으로 해 석할 수 있다. 이 때문에 통계적으로 유의한 차이가 나타나진 않았지만 Event가 2 6아지 진행되면서 점점 $\mathrm{A}$ 그룹의 칼끝 속도가 $\mathrm{B}$ 그룹에 비해 높아지는 것을 알 수 있다. 따라서 초기에는 마르쉬 동작에 비중을 높이 고, 왼발 앞꿈치가 지면에서 떨어져서 팡트 동작으로 연결하는 시점부터 속도를 올리는 형태가 더 우수한 기술 동작을 나타내는 것이라고 생각된 다. 4 명의 펜싱 숙련자와 5 명의 펜싱 초보자 간 팡트 동작의 속도를 비 교한 연구에서는 칼끝의 터치 속도가 다양한 조건 내에서 펜싱 초보자에 비해 숙련자가 더 빠른 속도를 보이는 것을 알 수 있었다(Yiou \& Do, 2000). 또한 펜싱 동작이 진행되는 초기에 엉덩관절과 무릎관절의 굴곡 각도가 더 높아진다면 칼끝의 속도가 더 빨라지는데 공헌을 한다고 하였 고, 이는 엉덩관절과 무릎관절의 굴곡이 높아지면 팡트의 런지 동작의 넓이가 넓어지게 되어 앞발의 움직임에 영향을 주고 이로서 칼끝의 속도 가 빨라지는 이점을 준다는 선행연구가 본 연구 결과와 어느 정도 일치 한다고 볼 수 있다(Bottoms et al., 2013). 본 연구에서 통계적으로 유의 하지는 않았지만 초기에는 A그룹이 B그룹에 비해 낮은 속도를 보이다가 마지막 Event로 갈수록 빨라지는 것을 볼 수 있었고, 무릎 각도가 $\mathrm{A}$ 그 룹이 Event 2 를 제외한 모든 Event에서 B그륩에 비해 더 큰 굴곡을 보 였으며, 앞발의 속도가 마지막 시점인 Event 5, 6에서 A그룹이 B그룹에 비해 더 빠른 속도를 보인 점에서 위와 같은 결론을 뒷받침한다고 볼 수 있는 것이다. 속도 요인 중 뒷발의 속도는 두 그룹 간 통계적으로 유의한 차이가 없었다. 앞에서도 언급했듯이 두 그룹의 기술 수준이 매우 뛰어 난 수준이고, 매우 근소한 차이이지만 올림픽 메달리스트인 A그룹이 국 제 대회 입상자 그룹인 B그룹에 비해 마지막 팡트 동작에서 앞발과 뒷발 의 의 속도가 Event 5 와 6에서 빠르다는 점에서 본 연구의 결과 값 비교 는 고무적이라고 볼 수 있겠다.

종합하면, 본 연구에서는 우수 그룹에게서 세 가지 특성을 볼 수 있었 다. 먼저 동작수행 시간에서는 펜싱 공격의 시작 시점에서는 A그룹이 더 오랜 시간을 소요하였고, 이 점이 뒤에 이어지는 동작의 속도를 올리는 결과를 보이게 되었는데, 소요시간 비율에서 전체 동작의 반 이상을 차 지하는 시간 비율을 보인데 반해 Phase 2에서 매우 낮은 비율을 보이면 서 Phase 4까지 소요시간이 B그룹에 비해 적게 나타났고, 마지막 팡트 동작에서만 더 많은 소요시간을 보여 공격의 시작과 끝 시점에서 더 집 중하는 동작 패턴을 보인 것으로 사료된다. 두 번째는. 칼끝의 속도 특성 이다. Event 1 에서 칼끝의 속도가 B그룹에 비해 약 $0.11 \mathrm{~m} / \mathrm{s}$ 느린 것을 볼 수 있는데, 이는 앞에서의 시간 비율과 관련되며, 공격 동작의 시작점 에서 매우 낮은 속도를 나타냈고 이러한 결과가 동작 수행 시간 비율을 높게 만드는 이유라고 볼 수 있는 것이다. 또한 Event가 진행되면서 칼 끝의 속도가 빨라지는 것을 볼 수 있는데 앞발의 속도가 마지막 Event 6 에서 $\mathrm{A}$ 그룹이 빠르게 나타난 결과를 보였는데 통계적 유의점은 발견되 지 않았지만 Event 3, 4, 5, 6에서의 더 큰 무릎 굴곡이 칼끝의 속도 및 앞발의 속도와 관련된다고 생각된다. 결과적으로, 운동학적 변인 중 신 체 관절의 각도에서는 통계적 유의점을 발견하지 못했지만 펜싱 동작의 시간 및 속도 변인에서 유의점을 발견하였고, 매우 우수한 기량을 보이 는 두 그룹에서 이러한 차이는 메달의 색이 달리지는 변인 차이라고 볼 
수 있겠다. 후속 연구에서는 근전도 센서를 이용하여 하지와 상지의 근 육 활성 패턴과 운동학적 변인을 함께 분석한다면 더 심도 있는 펜싱 종 목 스포츠과학 연구가 될 것으로 기대한다.

\section{결론 및 제언}

본 연구는 펜싱 마르쉬 팡트 동작 시 동작수행 시간(구간별 소요시간, 구 간별 소요시간 비율), 국면별 보폭 변화, 각 시점별 각도 요인(상지의 몸 통전경각, 팔꿈치각, 무릎각), 각 시점별 펜싱 칼끝의 속도 요인(앞발과 뒷발)을 올림픽 메달리스트 그룹(A그룹)과 국제대회 입상자 그룹(B그룹) 으로 나누어 각 요인별로 독립 $\mathrm{t}$-검정을 실시하여 결과를 비교하였다.

분석 결과 동작 수행 시간에서 두 그룹 간 차이를 보였고, 속도 요인에 서도 앞발에서 통계적으로 유의한 차이를 나타냈다. 하지만 몸통의 전 경각, 팔꿈치각, 무릎각에서는 두 그룹 간 통계적 유의점을 찾지 못했다. 이는 $\mathrm{A}$ 그룹과 $\mathrm{B}$ 그룹이 모두 최고의 기량을 발휘하는 매우 우수한 선수 라는 점에서 매우 근소한 시간과 속도의 차이를 제외한 동작의 디테일한 부분에서는 유사하다는 것을 나타내는 것이다. 더 자세히 설명하면, 마 르쉬 팡트 동작 시작 시점에서는 처음부터 빠른 동작을 하기 보다는 상 대의 움직임 상황에 살펴보면서 그에 따른 움직임을 생성할 수 있도록 하고 움직임이 시작해서 이어질 때 가속도를 붙여서 런지 동작의 마무리 에서 빠른 움직임으로 공격을 한다면 더 유용한 공격이 될 것으로 판단 된다. 또한, 마지막 공격 마무리 시 앞발의 속도를 더 빠르게 하면서 무 릎의 각도를 약 160 도로 유지하는 것이 매우 우수한 동작이라고 사료된 다. 따라서 앞에서 설명한 결과 및 두 그룹에서 유사한 결과를 보인 변인 값을 토대로 펜싱 초보자나 이제 펜싱을 시작하는 교육 대상자들에게 기 준을 제시하여 피드백을 제공한다면 매우 우수한 교육 및 경기 결과를 낼 것으로 판단된다.

\section{참고문헌}

Ahn. (2003). Kinematic Analysis of Marche Fente Motion in a Fleuret Attack Technique. Korean Journal of Sport Biomechanics, 13(3), 277-291.

Ahn. (1984). Electromyographic analysis of fente motion in fencing. Unpublished master's thesis. Chonnam National University Graduate School.

Bottoms, L., Greenhalgh, A., \& Sinclair, J. (2013). Kinematic determinants of weapon velocity during the fencing lunge in experienced épée fencers. Acta of bioengineering and biomechanics, 15(4), 109-113.

Castello, H. (1972). Fencing. Journal of Health, Physical Education, Recreation, 43(3), 58-64.

Gholipour, M., Tabrizi, A., \& Farahmand, F. (2008). Kinematics analysis of lunge fencing using stereophotogrametry. World $J$ Sport Sci, 1(1), 32-37.

Geil, M. D. (2002). The role of footwear on kinematics and plantar foot pressure in fencing. Journal of Applied Biomechanics, 18(2), 155-162.

Gutierrez-Davila, M., Rojas, F. J., Antonio, R., \& Navarro, E. (2013). Response timing in the lunge and target change in elite versus medium-level fencers. European Journal of Sport Science, 13(4), 364-371.

Harmenberg, J., Ceci, R., Barvestad, P., Hjerpe, K., \& Nyström, J. (1991). Comparison of different tests of fencing performance. International journal of sports medicine, 12(06), 573-576.

Chung. (2019). The Effect of Step-training on the Kinematical Variables of Marche Fente Motion in Fencing Sabre. The Korea Journal of Sport, 17(2), 1197-1206.

Kang. (1987). A study on the systemic reaction of volleyball players. Kyung Hee University Proceedings.

Kim. (2011). 2010 Soar to the world of Korean fencing!. Sport Science, 114, 63-68.

Kim. (2003). Yongsu Kim (2003). A study on the agonistic muscles of fencing fente action. Korea Sports Research, 14(5), 113-132.

Lee, Eom, Lim, Lim, Yoo, Shin, \& Sim. (2009). Physical education instructor training guide (fencing). Korea Sports Promotion Foundation, Korea Institute of Sport Science.

Lee. (1999). EMG analysis of upper extremity muscle during fencing stabbing action. Unpublished Master's Thesis. Hannam University Graduate School.

Lee, J. Y., Lee, S., \& An, J. S. (2018). Fente defence with occluded vision: The differences of anticipating accuracy and confidence as a spatial occlusion region and fencing expertise. Korean Journal of Sport Science, 29(4), 716-726.

Morris, N., Farnsworth, M., \& Robertson, D. G. E. (2011). Kinetic analyses of two fencing attacks-lunge and fleche. In ISBSconference proceedings archive. 
Park. (1974). A study on the correlation between reaction time and skill action time of fencing players. Kyung Hee University Proceedings.

Roi, G. S., \& Bianchedi, D. (2008). The science of fencing. Sports medicine, 38(6), 465-481.

Stewart, S. L., \& Kopetka, B. (2005). The kinematic determinants of speed in the fencing lunge. J Sports Sci, 23(2), 105.

Sinclair, J., Bottoms, L., Taylor, K., \& Greenhalgh, A. (2010). Tibial shock measured during the fencing lunge: the influence of footwear. Sports biomechanics, 9(2), 65-71.

Teichner, W. H. (1954). Recent studies of simple reaction time. Psychological Bulletin, 51(2), 128.

Yiou, E., \& Do, M. (2000). In fencing, does intensive practice equally improve the speed performance of the touché when it is performed alone and in combination with the lunge?. International journal of sports medicine, 21(02), 122-126.

Zhang, B., Chu, D., \& Hong, Y. (1999). Biomechanical analysis of the lunge technique in the elite female fencers. In ISBS-Conference Proceedings Archive.

Zappa, B., Legnani, G., Roi, G. S., \& Galli, M. (1999). Kinematic analysis of three fencing hits. In XVIIth ISB Congress, Calgary 685. 


\section{엘리트 펜싱 플뢰레 여자 선수 공격기술의 상지와 하지분절 움직임 분석}

\section{김태완 ${ }^{1}$, 최상협}

1 한국스포츠정책과학원 책임연구위원

2 제주스포츠과학센터 선임연구원

[목적] 본 연구에서는 국가대표 여자 플뢰레선수들을 대상으로 두 그룹의 선수들이 경기 상황에서 공격 시 상지와 하지의 분절(segment)별 메커니즘에 대해 운동학적 변인을 비교 분석하여 경기력향상에 도움을 주고자 한다.

[방법] 펜싱 마르쉬 팡트 동작 시 동작수행 시간(구간별 소요시간, 구간별 소요시간 비율), 국면별 보폭 변화, 각 시점별 각 도 요인(상지의 몸통전경각, 팔꿈치각, 무릎각), 각 시점별 펜싱 칼끝의 속도 요인(앞발과 뒷발)을 올림픽 메달리스트 그룹 (A 그룹)과 국제대회 입상자 그룹(B 그룹)으로 나누어 각 요인별로 독립 t-검정을 실시하여 결과를 비교하였다.

[결과] 분석 결과 동작 수행 시간에서 두 그룹 간 차이를 보였고, 속도 요인에서도 앞발에서 통계적으로 유의한 차이를 나타냈다. 하지만 몸통의 전경각, 팔꿈치각, 무릎각에서는 두 그룹 간 통계적 유의점을 찾지 못했다.

[결론] 이는 A 그룹과 B 그룹이 모두 최고의 기량을 발휘하는 매우 우수한 선수라는 점에서 매우 근소한 시간과 속도의 차 이를 제외한 동작의 디테일한 부분에서는 유사하다는 것을 나타내는 것이다. 따라서 관절 각도의 결과 값의 평균은 펜싱 초보자나 이제 펜싱을 시작하는 교육 대상자들의 피드백 지표가 될 것이고, 이와 더불어 A 그룹의 시간 요인과 속도 요인 결과에 대한 수행 목표를 참고하여 훈련을 한다면 매우 우수한 교육 및 경기 결과를 낼 것으로 판단된다.

주요어

마르쉬, 팡트, 펜싱, 동작 시간, 속도 